\title{
POR UMA EDUCAÇÃO PROFISSIONAL DE TECNÓLOGOS A PARTIR DOS CONCEITOS DE OMNILATERALIDADE E POLITECNIA
}

\author{
Ari Paulo Jantsch (In memoriam) ${ }^{1}$ \\ Universidade Federal de Santa Catarina \\ Luiz Alberto de Azevedo \\ Instituto Federal de Educação, Ciência e Tecnologia de Santa Catarina \\ lazevedo@ifsc.edu.br
}

\section{RESUMO}

O presente trabalho objetiva debater a educação profissional dos tecnólogos a partir dos conceitos de Politecnia e Omnilateralidade. Nos dias atuais, com as novas configurações do mundo do trabalho e os debates em bases teórico-metodológicas críticas que defendem uma educação científico-tecnológica sem compromisso com a lógica do mercado, passouse a requerer uma educação geral e recolocar os conceitos de politecnia e omnilateralidade nas construções curriculares. O Conselho Nacional da Educação (CNE) destaca que a educação profissional deve ser vista para além das demandas do mercado de trabalho. Também indica que a elaboração de currículos para a Educação Profissional deve ser pautada por princípios, como os da flexibilidade, da interdisciplinaridade e da contextualização. Contudo, o conjunto de explicitações do CNE não alcança uma concepção emancipadora. Daí a relevância do presente estudo: além de oferecer um conceito denso de Educação Tecnológica, trata da inserção decisiva dos conceitos de politecnia e omnilateralidade (plena formação profissional) na educação profissional de tecnólogos na perspectiva emancipadora.

Palavras-chave: Educação Tecnológica, Politecnia, Omnilateralidade, CST, Currículo.

\section{FOR A PROFESSIONAL EDUCATION OF TECHNOLOGISTS FROM THE CONCEPTS OF POLYTECHNICS AND OMNILATERALITY}

\section{ABSTRACT}

This work tackles the professional education of technologists from concepts of polytechnics and omnilaterality. Nowadays, with the new configurations of the world of work and the debates in critical theoretical-methodological bases, which advocate a scientific-technological education without compromise with the logic of the labor market, one requires a general education and replace the concepts of polytechnics and omnilaterality in curricular constructs. The National Council of Education (NCE) states that the professional education must be seen beyond the demands of the labor market. It also indicates that the working of curricula for professional education should be based on principles, like flexibility, interdisciplinarity, contextualization. Nevertheless, the set of explanations of NCE do not reach an emancipated conception. Hence the relevance of this study: besides offering a dense concept of technological education, it deals with the decisive insertion of polytechnics and omnilaterality (complete professional formation) in the professional education of technologists from the emancipated point of view.

Keywords: Technological Education, Polytehnics, Omnilaterality, Technological Graduation Courses, Curriculum. 


\section{Pensando para além do capital}

O presente trabalho objetiva debater a educação profissional dos tecnólogos a partir dos conceitos de politecnia ${ }^{3}$ e omnilateralidade ${ }^{4}$, os quais são decisivos para uma educação para além do capital. Esse caráter fica potencializado ao consideramos a avaliação de Mészáros (2003, p.21) de que "dada a forma em que se realizou a deformada tendência globalizante do capital - e que continua a se impor" - "seria suicídio encarar a realidade destrutiva do capital como pressuposto do novo e absolutamente necessário modo de produzir as condições sustentáveis da existência humana".

Pensando além da sociabilidade do capital e sendo fato a existência de um grande contingente de profissionais os quais têm sido sistematicamente encantados pela esfera empresarial - que promove a produção e a sustentação de um processo espiralado de novas tecnologias aquém das necessidades da existência humana - no atual processo civilizatório, firmamos posição epistemológica e política em favor da formação tecnológica ancorada nos conceitos de politecnia e omnilateralidade.

É notório que os detentores do capital - empunhando as bandeiras da "era tecnológica" e do "fim da história" - fagocitem sociedades e embrenhem-se determinantemente no tecido social pela via do encantamento das 'maravilhas' e dos 'milagres' do mercado. Trata-se, portanto, da anti-tecnologia do ser social ${ }^{5}$ para além da sociabilidade do capital.

Com as novas configurações do mundo do trabalho e os debates em bases teóricometodológicas críticas que defendem uma educação científico-tecnológica sem compromisso com a lógica do mercado sob o capital, passou-se a requerer uma educação geral e a recolocar os conceitos de politecnia e de omnilateralidade nas construções curriculares em âmbito brasileiro ${ }^{6}$.

Nesse contexto de debate, conselheiros do $\mathrm{CNE}^{7}$ passaram a afirmar que a educação profissional brasileira deve ser vista para além das demandas do mercado de trabalho. Seria, contudo, ingenuidade esperarmos que o CNE, também expressão da categoria da contradição, não incorresse em alguma ambiguidade. Nesse sentido, destacamos que no dia 2 de dezembro de 2002, conselheiros do CNE, mediante o Parecer CNE/CP n ${ }^{\circ}$ 29/2002, manifestaram-se sobre as Diretrizes Curriculares Nacionais Gerais para a Educação Profissional de Nível Tecnológico, afirmando que

[...] o grande desafio é o da oferta de uma educação profissional de nível superior, fundamentada no desenvolvimento do conhecimento tecnológico em sintonia com a realidade do mundo do trabalho [leiase: na sociabilidade do capital], pela oferta de programas que efetivamente articulem as várias dimensões da educação, trabalho, ciência e tecnologia. (BRASIL, 2008, p.341, grifo nosso).

Ainda nesse mesmo Parecer (CNE/CP n ${ }^{\circ}$ 29/2002, p.374), conselheiros interpretam que "a elaboração de currículos da Educação Profissional deve ser pautada, dentre outros fatores, pelos princípios da flexibilidade, da interdisciplinaridade e da contextualização". Observamos, ainda, que, no caso da educação profissional dos tecnólogos, conselheiros do CNE manifestam-se de uma forma bastante tímida, ou seja, nas suas revelações institucionais destacadas não apresentou o seu entendimento sobre o conceito dessa modalidade de educação, deixando a organização curricular dos CST a critério de cada instituição, como se elas não estivessem constantemente sendo determinadas pela lógica do mercado. Assim, as poucas orientações para a organização dos currículos relativos à 
educação profissional dos tecnólogos advêm do Artigo 43 da Lei n ${ }^{0}$ 9.394/1996 (LDB), inciso II, que aponta para a formação de "diplomados nas diferentes áreas de conhecimento, aptos para a inserção em setores profissionais e para a participação no desenvolvimento da sociedade brasileira, e colaborar na sua formação continuada" (BRASIL, 1996).

Daí a relevância do presente trabalho: indicar, a partir do debate acima mencionado, uma concepção de Educação Tecnológica que incorpore os conceitos de politecnia e omnilateralidade, com vistas a uma formação ampliada e crítica, na implantação dos CST diante das ambíguas orientações do Estado brasileiro, ora apontando para o alinhamento ao mercado, ora apontando, timidamente, para além da lógica do mercado.

\section{O embate mercado versus politecnia e omnilateralidade}

No presente trabalho, propomos, ao debater a educação profissional dos tecnólogos, ou seja, as atuais ofertas de $\mathrm{CST}^{8}$ tão reivindicados pelo "mercado" na atual sociabilidade do capital, uma educação científico-tecnológica que esteja centrada nos conceitos de politecnia e de omnilateralidade. A nosso ver, tais conceitos, articulados entre si, constituem os construtos epistemológico-políticos que exigem uma realização da educação profissional dos tecnólogos para além da lógica do mercado sob a sociabilidade do capital. "Mercado" esse que, na atual sociabilidade do capital, frequentemente reclama da falta de profissionais qualificados/competentes, muitas vezes confundindo qualificação e competência e, noutras vezes, colocando os dois conceitos como complementares entre si. O próprio $\mathrm{CNE}$, considerando a ação de seus conselheiros, incorre, aqui e acolá, nessa confusão.

Entendemos que a qualificação profissional contemporânea não garante, nem mesmo, a competência no sentido estreito da formatação do trabalhador conforme os padrões, pacotes e/ou modelos tecnológicos requeridos pelas empresas comprometidas com a valorização do valor (capital) e, portanto, imanentemente (re)produtoras da unilateralidade no tocante à qualificação-competência articulada no contexto da atual sociabilidade do capital. Essa percepção está devidamente embasada no movimento do capitalismo, que ao transformar ciência e tecnologia em forças produtivas, contraditoriamente, anuncia a necessidade da ruptura do dualismo estrutural educacional, em face de necessitar, para sua sobrevivência, da crescente intelectualização do mundo da produção de forma a manter a organicidade latente do trabalho produtivo.

Conforme afirma Luckács (1979, p.16), “o próprio homem que trabalha é transformado pelo seu trabalho; ele atua sobre a natureza exterior e modifica, ao mesmo tempo, a sua natureza; "desenvolve as potências nela ocultas"” e, ainda, "subordina as forças da natureza 'ao seu próprio poder", de maneira que "os objetos e as forças da natureza são transformados em meios, em objetos de trabalho, em matérias-primas, etc". $\mathrm{O}$ autor, ainda, afirma que "o homem que trabalha "utiliza as propriedades mecânicas, físicas e químicas das coisas, a fim de fazê-las atuar como meios para poder exercer seu poder sobre outras coisas, de acordo com sua finalidade"”. Assim, a qualificação por nós cogitada não abdica da ideia das condições plenas de realização, pelo profissional, de um trabalho científico-tecnológico demarcado, porém com bases científico-tecnológicas universais. No entanto, há que considerar esse ser humano como Ser social e não reduzido à força de trabalho (assujeitado) em sua relação com a tecnologia, relacionado a uma competência específico-passageira no movimento da produção da existência e da valorização do valor, como no caso da sociabilidade do capital. 
Por outro lado, destacamos que não estamos fazendo qualquer apologia a um possível receituário que o egresso da educação profissional de tecnólogos, ao se formar, leve consigo para a sua vida profissional, visto como um pacote de auto ajuda que o oriente, a partir dessa etapa, a agir como uma outra máquina ou equipamento do ambiente ao qual se insere, mediante uma rotina previamente programada e possível de ser alterada a qualquer momento. Pelo contrário, os pressupostos da politecnia e da omnilateralidade implicam uma formação necessariamente para além de qualquer receituário e de qualquer treinamento que, apesar das aparências, mantêm o trabalhador desqualificado científicotecnologicamente e, portanto, com uma educação científico-tecnológica precária.

A contradição da sociabilidade do capital, quando se trata da formação científicotecnológica, aparece forte, pois, ao mesmo tempo em que o mercado exige profissionais prontos para a realização imediata de tarefas inerentes aos mais recentes nichos científicotecnológicos, via de regra unilaterais, não qualifica os mesmos para uma apropriação científico-tecnológica que ultrapasse uma competência específico-passageira no movimento da valorização do valor. Seria o espaço da educação científico-tecnológica público-estatal a possibilidade de atenuar ou superar a contradição da sociabilidade do capital acima mencionada, uma vez que se evidencia, no atual contexto acadêmico sob a tutela empresarial, uma relação de imbricamento entre alguns conceitos como educação, mercado, currículo"?

Para nos situarmos no contexto em questão, referenciamo-nos em algumas informações destacadas por conselheiros do CNE, apropriadas do Instituto Nacional de Estatutos e Pesquisas Educacionais Anísio Teixeira (INEP), cuja autarquia ministerial relata em "Resultados e tendências da educação superior do Brasil" (BRASIL, 2000, p.9) que "em 1999 tínhamos exatos 442.835 alunos em cursos de graduação das instituições federais de ensino superior". Nesse documento elaborado pelo INEP (BRASIL, 2000), profissionais da autarquia relatam que no período de 1994 a 1999, a matrícula no ensino superior expandiu-se em 22\% e que a expansão desses cursos em 1999 foi de 8,4\%. Esta tendência de crescimento, segundo profissionais do INEP, parece se manter, já que o número de ingressantes no vestibular aumentou 30\% nos últimos cinco anos, induzido, provavelmente, pelo crescimento médio de 35,4\% do Ensino Médio, no espaço de tempo compreendido entre 1996 e 1999, quando o ensino superior cresceu 27,3\%, no mesmo período.

$\mathrm{Na}$ premissa de focar a discussão, fazemos referência ao "Censo da educação superior de 2004" (BRASIL, 2005), no qual profissionais dessa autarquia apontam que os Centros Federais de Educação Tecnológica e Faculdades de Tecnologia, instituições que trabalham a educação profissional de tecnólogos, representavam $7,4 \%$ do total das instituições do sistema e tiveram o mais expressivo crescimento - $54,8 \%$ no ano - de todos os modelos de organização acadêmica. Trata-se, portanto, de instituições voltadas para um modelo de educação dirigida quase que, exclusivamente, para o mercado de trabalho, numa perspectiva de "gôndola de supermercado". Outra informação que julgamos ser relevante utilizar para mediar o debate é a de que, em 1999, o Censo da Educação Superior registrava 16 instituições; em 2002, chegou a 53 e, posteriormente, em 2004, a 144 instituições, representando, segundo o INEP, um crescimento de $800 \%$ em cinco anos (BRASIL, 2005, p.15).

A expectativa de crescimento relativa à educação superior vislumbrada por profissionais do INEP (BRASIL, 2005, p.47), portanto, se consumou: "Ingressaram na educação superior, em 2004, 1.302.298 estudantes, 3,1\% a mais que no ano anterior". Chama-se, entretanto, a atenção para o fato sobre a origem acadêmica dessa modalidade de educação que integra também a educação superior, a Educação Tecnológica, que nasce 
pública. Porém, a partir do ano de 2001, o setor privado inicia sua inserção neste setor com oito $(23,5 \%)$ instituições; em 2002 atinge $22(41,5 \%)$ instituições enquanto o setor público apresentava 31 (58,49\%); em 2003, o setor privado, com 54 (58,06\%) instituições, ultrapassa o setor público com 39 (41,93\%). Em 2004, chegou-se a 144 instituições, sendo $49(34,02 \%)$ públicas e $95(65,97 \%)$ privadas, explicitando claramente o interesse desse setor por essa modalidade de educação, também declarado como educação dirigida para o mercado de trabalho e estabelecendo tendências, em face de sua significativa presença.

No que se refere a cursos e vagas, profissionais do INEP (BRASIL, 2005) informam que, em 1999, os Centros de Educação Tecnológica e Faculdades de Tecnologia ofereciam 74 cursos; em 2001, 183 cursos, representando um crescimento de 147,3\%. Em 2003, 495 cursos, representando um crescimento de 170,5\% com relação ao ano de 2001 e de 568,9\% em relação ao ano de 1999. O Censo de 2004 (BRASIL, 2005) ainda revela que nesse ano foram criados, no setor privado, 209 cursos, acarretando um crescimento de $115,5 \%$. Quanto às vagas, o INEP divulga que, no ano de 2004, os Centros de Educação Tecnológica ofereceram 74.866 vagas, representando 3,2\% das 2.318 .769 vagas oferecidas no sistema de educação superior. Um outro dado que se julga relevante inserir no debate é a seguinte declaração desenvolvida por profissionais do INEP:

Registre-se que no setor público, pela primeira vez desde 1999 ,
ingressaram mais estudantes do que o número de vagas efetivamente
oferecidas. Ingressaram no setor público 19.749 estudantes, tendo sido
oferecidas somente 18.469 vagas - o que indica que foi feito um esforço
incomum, especialmente nos Centros Federais, para abrigar 1.280
estudantes a mais. Toda ociosidade de vagas, portanto, pertence ao setor
privado, onde praticamente $60 \%$ das vagas oferecidas não foram
ocupadas. (BRASIL, 2005, p.38).

Com relação a resultado, o INEP (BRASIL, 2005) veicula que a Educação Superior Tecnológica, em 2004, graduou um total de 11.759 estudantes, representando 1,9\% dos 626.160 graduados da educação superior, e que o setor público, que detém o maior número de matrículas, participa com 55,3\% do total, sendo que deste, $71,2 \%$ são decorrentes da participação das instituições federais. Profissionais do INEP (BRASIL, 2005, p.45) concluem que "Os Centros de Educação Tecnológica e as Faculdades de Tecnologia, embora representem apenas $7,4 \%$ do total de instituições do sistema", isto é, educação superior, "foram os que tiveram o mais expressivo crescimento de todos os modelos de organização acadêmica, atingindo $54,8 \%$ no ano, mostrando uma inequívoca procura por este modelo de educação profissionalizante".

No que se refere à questão do crescimento dos cursos de educação tecnológica, o Censo da Educação Superior 2007 (BRASIL, 2009, p.9) revela que o crescimento desses cursos "foi ligeiramente maior do que o observado no ano anterior, embora nos centros universitários tenha sido registrado um incremento de 28,1\%"; segundo informações do INEP, foram "registrados cerca de 700 novos cursos no Brasil, a maior parte deles ofertados pelas faculdades e universidades". O INEP (BRASIL, 2009, p.15) dá a conhecer que "em 2007 foram ofertadas 394.120 vagas nos cursos de Educação Tecnológica, registrando um acréscimo de $23,6 \%$ em relação a 2006" e que "as IES privadas são responsáveis por mais de $90 \%$ dessa oferta", além disso, "o número de concluintes nos cursos de Educação Tecnológica também aumentou entre 2006 e 2007, quando foram registrados 70.666 concluintes, ou seja, 30\% de crescimento no período" (BRASIL, 2009, p.17). 
Para demonstrar essa tendência pelos profissionais tecnólogos, fazemos referência à pesquisa "Mercado de Trabalho para o Engenheiro e Tecnólogo no Brasil", divulgada pelo Sistema Indústria em parceria com o Conselho Federal de Engenharia, Arquitetura e Agronomia (CONFEA), realizada em 2007, num universo de 1.098 empresas, de todos os portes e setores e, ainda, oriundas de todas as regiões do país. Nesta, a pesquisa revela que do total das empresas entrevistadas, 39\% disseram que contrataram tecnólogos, numa média de 7,5 tecnólogos por empresa; a pesquisa, ainda, indica que, até o momento, a qualidade dos tecnólogos formados parece estar satisfazendo o mercado, "que lhes dá uma média de 7,1, com $70 \%$ dos que fizeram a avaliação atribuindo-lhes notas entre sete e dez" (CNI, 2008, p.42).

Com relação à postura acadêmica das instituições educacionais, a pesquisa revela existir um distanciamento entre o que as escolas ensinam e o que o mercado necessita, sendo que a principal queixa é a falta de prática profissional, levando as empresas a investirem, mediante o uso de vários instrumentos como programas de trainee, na adaptação do profissional à realidade da empresa. Seria o aligeiramento da forma acadêmica que está provocando essa insatisfação? Entre as sugestões apresentadas pelas empresas, e aí é importante destacar que não se trata especificamente de um determinado profissional, mas sim dos profissionais que de uma forma geral trabalham com tecnologia, destacamos:

- Um ensino mais prático, em que um embasamento teórico firme não impeça que a aplicação prática da teoria seja aprofundada e se aproxime mais das condições, utilizando instrumentos similares aos que existem no mercado.

- A oferta de cursos de especialização de foco restrito, porém em profundidade para áreas de interesse específico das empresas.

- Evitar a preocupação só com os aspectos técnicos, colocando mais ênfase no trabalho em equipe, na capacidade de liderança e de gerenciamento de equipes e projetos complexos. (CNI, 2008, p.36, grifo nosso).

Estamos, pois, assistindo ao grito próprio da atual sociabilidade do capital e, ao mesmo tempo, a sua contradição, porque a sociedade moderna, como interpreta Saviani (2003, p.134), "revoluciona constantemente as técnicas de produção e incorpora os conhecimentos como força produtiva". Assim, quanto mais o capital se apropria da ciência e, principalmente da tecnologia, em face de suas finalidades imediatistas, e a domina numa perspectiva própria da sua sociabilidade, mais necessidade ele sente do trabalho científicotecnologiamente qualificado, estabelecendo uma situação de dualidade e crise entre o que historicamente se denomina de trabalho intelectual e trabalho manual, porque é exigido do trabalhador um conjunto de conhecimentos científicos e tecnológicos para a compreensão, cada vez maior, do processo tecnológico, exemplarmente quando se trata de "projetos complexos".

Sem necessidade de maior explicitação, podemos afirmar que, embora o Estado brasileiro sinalize a educação profissional dos tecnólogos para além dos critérios do mercado, em nenhum momento aponta para uma educação científico-tecnológica que incorpore os conceitos de politecnia e de omnilateralidade, nem confirma, em seu discurso como um todo, tal anúncio. O mercado sob a sociabilidade do capital continua, pois, intocável e o discurso por uma educação científico-tecnológica para além do mercado não passa de retórica, eis que o avanço da Educação Tecnológica no espaço público-estatal não tem significado, de fato, um movimento para além do mercado, muito pelo contrário, o mote da atualidade é uma ação do ministério da educação voltada exclusivamente aos Arranjos Produtivos Locais (APL). 


\section{A visão do Conselho Nacional de Educação e a ausência dos conceitos de politecnia e omnilateralidade nessa perspectiva de educação}

O enfoque utilitarista e reducionista da educação profissional dos tecnólogos, originário da formação de meros tarefeiros, foi superado, pelo menos do ponto de vista da legislação e das próprias exigências do mercado, em decorrência do desenvolvimento acelerado da ciência e, principalmente, da tecnologia, as quais foram, de forma selvagem e utilitariamente, apropriados pelo capital ${ }^{10}$. A respeito da oferta da formação de Tecnólogos, o Parecer CNE/CES n. ${ }^{\circ}$ 436/2001 (BRASIL, 2008, p.318) não deixa dúvidas quanto ao caráter do perfil a que se destina: "a egressos do Ensino Médio, Ensino Técnico e de matriculados e a egressos do ensino superior", de forma que esse futuro profissional deva estar apto a desenvolver, de forma plena e inovadora, atividades em uma determinada área profissional, com formação específica para:

a) Aplicação, desenvolvimento, pesquisa e inovação tecnológica e a difusão de tecnologias.

b) Gestão de processos de produção de bens e serviços.

c) Desenvolvimento da capacidade empreendedora.

Prado (2004) concorda com essa visão de conselheiros do CNE, ao se manifestar, argumentando que não se trata de cursos "aligeirados" ou "diminuídos", mesmo porque as Diretrizes Curriculares Nacionais para o Ensino Tecnológico, de acordo com cada área profissional, prevêem uma organização curricular com cerca de $40 \%$ de conteúdos práticos, associados, entretanto, a uma formação teórica. Nesse mesmo Parecer (2001), ainda se observa a preocupação de conselheiros do CNE ao deixar claro que as propostas pedagógicas desses cursos devem ter sintonia com o meio produtivo e com as necessidades da sociedade e, portanto, numa condição de não atrelamento, porque se trata de uma ação primeira: Educação e Formação do Ser, ou seja, antes de tudo, é preciso compreender que se está reportando a um sujeito social.

Os integrantes da comissão bicameral no Parecer CNE/CP n. ${ }^{\circ}$ 29/2002 levantam a questão da antiga e retrógrada segmentação desenfreada dos tradicionais cursos superiores de graduação, chamando a atenção para o fato da interdisciplinaridade na formação integrada desses profissionais, possibilitando:

a) Incentivar o desenvolvimento da capacidade empreendedora e da compreensão do processo tecnológico, em suas causas e efeitos.

b) Encorajar a produção e a inovação científico-tecnológica e suas respectivas aplicações no mundo do trabalho.

c) Desenvolver competências profissionais tecnológicas, gerais e específicas, para a gestão de processos e a produção de bens e serviços.

d) Propiciar a compreensão e a avaliação dos impactos sociais, econômicos e ambientais resultantes da produção, gestão e incorporação de novas tecnologias;

e) Promover a capacidade de continuar aprendendo e de acompanhar as mudanças nas condições do trabalho, bem como propiciar o prosseguimento de estudos em cursos de pós-graduação.

f) Adotar a flexibilidade, a interdisciplinaridade, a contextualização e a atualização permanente dos cursos e seus currículos.

g) Garantir a identidade do Perfil Profissional de conclusão do curso e da respectiva organização curricular. (BRASIL, 2008, p.356-357). 
A comissão bicameral no Parecer CNE/CP n. ${ }^{0}$ 29/2002 reafirma que os CST se caracterizam como cursos superiores de graduação; que devem contemplar a formação de profissionais para além da capacidade de desenvolver, de forma plena e inovadora, atividades em uma determinada área e formação específica; chama a atenção das instituições de ensino para a identificação de critérios e referenciais claros e, ainda, de sua responsabilidade na oferta desses cursos, como o apontado neste Parecer:

a) Natureza: certas áreas são, por natureza, essencialmente científicas e outras essencialmente tecnológicas. No primeiro caso, por exemplo, matemática, comporta cursos de Bacharelado, e não de Tecnologia. No segundo, por hipótese, informática, comporta cursos, em que a ênfase da formação e da atuação do profissional situa-se, fortemente, tanto no campo da ciência quanto no da tecnologia.

b) Densidade: a formação do tecnólogo é, obviamente, mais densa em tecnologia. Não significa que não deva ter conhecimento científico. O seu foco deve ser o da tecnologia, diretamente ligada à produção e gestão de bens e serviços. A formação do bacharel, por seu turno, é mais centrada na ciência, embora sem exclusão da tecnologia. Trata-se, de fato, de uma questão de densidade e de foco na organização do currículo.

c) Demanda: é fundamental que tanto a oferta de formação do tecnólogo como do bacharel correspondam às reais necessidades do mercado e da sociedade. Há uma tendência perniciosa de se imaginar e supor certa demanda comum, tanto do tecnólogo como do bacharel. Às vezes, os dois juntos, para a mesma área, sem perfis profissionais distintos, acarretam confusões nos alunos e no próprio mercado de trabalho. É necessário clareza na definição de perfis profissionais distintos e úteis.

d) Tempo de formação: é muito difícil precisar a duração de um curso de formação de tecnólogo, objetivando fixar limites mínimos e máximos. De qualquer forma, há um relativo consenso de que o tecnólogo corresponde a uma demanda mais imediata a ser atendida, de forma ágil e constantemente atualizada.

e) Perfil: o perfil profissional demandado e devidamente identificado constitui a matéria primordial do projeto pedagógico de um curso, indispensável para a caracterização do itinerário de profissionalização, da habilitação, das qualificações iniciais ou intermediárias do currículo e da duração e carga horária necessárias para a sua formação. (BRASIL, 2008, p.362-363)

Como princípios norteadores para a educação profissional dos tecnólogos, ou seja, para a construção dos projetos pedagógicos relativos à oferta de CST, conselheiros do CNE (2002) apontam aqueles enunciados pelos incisos destacados do Artigo 3. ${ }^{\circ}$ da Lei $n^{\circ}$ 9.394/1996, dentre os quais, no presente caso: (II) Liberdade de aprender, ensinar, pesquisar e divulgar a cultura, o pensamento, a arte e o saber; (III) Pluralismo de ideias e de concepções pedagógicas; e (XI) Vinculação entre a educação escolar, o trabalho e as práticas sociais.

O explicitado nesse item trata da concepção de que o Estado brasileiro tem da educação profissional dos tecnólogos de forma geral e, hoje, dos CST de forma singular, procurando, com essa explicitação conceptiva, orientar, a partir do CNE, as instituições educacionais que apresentam tais ofertas acadêmicas. O interessante a se observar, todavia, é que o Estado jamais desvincula educação-sociedade-mercado e não ultrapassa o que os ideólogos da sociabilidade do capital estão apregoando mundo a fora. Embora a visão 
explicitada pelos representantes do Estado reconheça o movimento da realidade em sua totalidade, não cogita, uma única vez sequer, sua superação.

Reconhecemos que a formação dos profissionais tecnólogos, segundo a visão do CNE, considerando sua natureza, foco e densidade, apresenta forte impacto nas tecnologias. Contudo, se considerarmos uma educação para além dos critérios do mercado, como o próprio CNE chega a reconhecer, isso não justifica um tratamento educacional reducionista, isto é, sem cogitar os conceitos de politecnia e omnilateralidade de forma articulada. Consideramos que a educação profissional dos tecnólogos, mesmo seguindo o movimento da atual sociabilidade do capital, deva se fundar pelo menos nos princípios educativos da gratuidade, laicidade e educação politécnica, pois estão, pelo menos a partir do discurso oficial, direcionados aos interesses da sociedade de uma forma mais ampla que o mercado sob a ótica da valorização do valor.

\section{Algumas considerações finais}

Em primeiro lugar, gostaríamos de reconhecer que, embora o Estado brasileiro tenha se movimentado coerentemente com o movimento do capital, a I Conferência Nacional de Educação Profissional e Tecnológica (CONFETEC), realizada pelo MEC no decorrer do ano de 2006, com a participação de mais de dez mil pessoas, permitiu um debate em que o grito da atual sociabilidade do capital e o seu caráter contraditório se explicitasse no tocante à educação tecnológica. É importante considerar que antecederam à CONFETEC, 27 conferências estaduais com a participação de todos os segmentos que integram a educação profissional e tecnológica, compreendendo a rede federal, estadual, municipal, comunitária e privada, produzindo, segundo o MEC, 900 propostas. Nessa oportunidade, verificou-se o desabrochar de um discurso oficial rasgado em favor da educação profissional e tecnológica, dentre os quais se destacam os seguintes trechos do estafe administrativo do MEC:

Haddad: De uma coisa estou absolutamente convicto: temos de dedicar boa parte da agenda da educação deste país ao tema educação profissional e tecnológica. Tenho igual convicção de que o resgate de um considerável contingente de nossa juventude, hoje fora da escola - refirome aos jovens de 15 a 17 anos que não estão matriculados nas escolas públicas do país; estamos falando de algo em torno de 1,8 a dois milhões de jovens - é uma tarefa da educação profissional, a ser desenvolvida pelas redes de formação inicial, de nível superior de todo o nosso sistema, o que vai exigir um grande esforço, tanto federal quanto estadual, para, depois de atrair essa juventude, acolhê-la nos bancos escolares. Temos de reconquistá-la, encontrar uma maneira de sensibilizá-la, apoiá-la, estimulá-la a voltar para a escola. Tenho certeza de que a educação profissional é o maior atrativo que lhe podemos oferecer. (BRASIL, MEC, 2007, p.13, grifo nosso).

Pacheco: Esta conferência, que hoje se inicia, insere-se nessa conjuntura extraordinária da nossa história em que desmoronam as últimas oligarquias e se abrem espaços para o mundo do trabalho, verdadeiro gerador das riquezas deste país. Para que isso se torne realidade, é necessário dar aos trabalhadores e trabalhadoras não apenas a qualificação profissional importante e necessária, mas também os instrumentos indispensáveis ao pleno exercício de sua cidadania. (BRASIL, MEC, 2007, p.15, grifo nosso). 
Há de se reconhecer que, dentre os resultados dos eventos mencionados, apareceu a ideia de uma educação que possibilitasse condições de aprender a pensar, estudar e dirigir, perpassada pelo desenvolvimento dos valores fundamentais do humanismo - tais como a autodisciplina intelectual e a autonomia - e envolvendo o trabalho manual e intelectual. Contudo, nem isso é realizado, pois tais premissas têm permanecido, mormente, na retórica, o que pode ser constatado no trecho do discurso de Frigotto.

Com efeito, um dos equívocos mais frequentes e recorrentes nas análises da educação no Brasil, em todos os seus níveis e modalidades, tem sido o de tratá-la em si mesma e não como constituída e constituinte de um projeto dentro de uma sociedade cindida em classes, frações de classes e grupos sociais desiguais e com marcas históricas específicas. (FRIGOTTO, 2007, p.243).

Está visível, portanto, que os cursos de tecnólogo e os cursos sequenciais de formação específica são cursos destinados a uma determinada casta da sociedade brasileira, que sequer cogita sobre as reais características desses cursos. Nesse sentido, é exemplar a manifestação da mídia brasileira, que em 2008 veiculou algumas manchetes sobre os cursos de tecnologia: em 15 de junho: "Tecnólogos lutam para serem aceitos em concursos no setor público"; em 23 de setembro: "Petrobrás recusa contratação de tecnólogos". Nesse sentido, outro destaque aparece no documento intitulado "Princípios norteadores das engenharias nos Institutos Federais", veiculado no Portal MEC/SETEC, com o seguinte dizer:

Neste contexto, reforça-se como fator decisivo para o desenvolvimento da nação brasileira a necessidade de profissionais especializados com sólida formação acadêmica em diversos setores da economia, como na área tecnológica, com destaque para os cursos de engenharia. $\mathrm{O}$ crescimento precisa ser "engenheirado". A questão dos cursos superiores da área das engenharias faz-se cada vez mais emblemática em duas dimensões indissociáveis: na qualidade da formação acadêmica a ser oferecida e na quantidade de engenheiros necessários para atender às demandas do crescimento sustentável do país. (BRASIL, 2008, p.5)

Mediante esses fatos, questionamo-nos: e o que havia sido cantado em verso e prosa sobre os tecnólogos, não serve mais? E qual o encaminhamento dado àquele discurso proferido na I CONFETEC? Em segundo lugar, consideramos que é preciso transpor a realidade do trabalhador unilateral, adotando uma perspectiva radical, que implique a formação total própria da estreita articulação dos conceitos de politecnia e de omnilateralidade (ver notas . $^{\circ} 1$ e 2 ).

A forma como a educação profissional dos tecnólogos vem se estruturando, todavia, não possibilita uma mudança de postura, ou seja, a superação da divisão entre teoria e prática e da unilateralidade própria da sociabilidade do capital, transpondo a educação utilitária voltada apenas para o mercado de trabalho. O Parecer CNE/CES n. ${ }^{\circ}$ 436/2001 (p.313), não faz mais do que destacar que as instituições educacionais ministrantes desses cursos deverão se pautar por um processo educacional "que favoreça, de modo permanente, a transformação do conhecimento em bens e serviços, em benefício da sociedade". 
Outra questão a ser observada nesse contexto é que, mesmo essa modalidade de educação sendo destinada à especialização dos educandos, ela (educação superior) não se articula com o conjunto do processo produtivo nem possibilita que, como interpreta Saviani (2007, p.161), "participem plenamente da vida cultural, em sua manifestação mais elaborada, todos os membros da sociedade, independentemente do tipo de atividade profissional a que se dediquem".

Assim, em terceiro lugar, para transpor minimamente a presente organização pedagógica da educação profissional dos tecnólogos, propomos algumas ações que indiciam a concepção de educação politécnica, denominadas por Pérez (2004, p.9-10) de precisões pedagógicas, tais como:

- Recuperar a compreensão dos princípios científicos e tecnológicos dos processos de trabalho, de forma a possibilitar que o educando adquira um saber-fazer tecnológico que convirja para um trabalho criativo, em que predomine o componente intelectual.

- Trabalhar valores e atitudes não apenas relacionados com o trabalho e com a produção, mas com o mundo em sua totalidade, com o que se torna ainda mais decisivo o pensar crítico, a compreensão do contexto e os condicionantes sociais, econômicos e políticos.

Finalmente, imbuídos dos pressupostos apresentados e convictos de que a sociedade se encontra em permanente transformação porque esta é construção deste mesmo ser humano, que ao produzi-la também se modifica e se potencializa sob uma perspectiva de autonomia e independência do grupo dominante, interpretamos que às instituições educacionais que atuam no sentido da educação tecnológica incorporem a pronta inserção dos conceitos de politecnia e de omnilateralidade de forma articulada, visando uma formação densa e ampliada e que se ponha para além dos critérios do mercado sob a sociabilidade do capital. Ademais, consideramos que os princípios de flexibilidade e de interdisciplinaridade, tidos como um grande avanço no movimento educacional pelos ideólogos do capital e pelo Estado brasileiro, sequer atendem à busca de superação das contradições postas no movimento societário do próprio capital, em face de manter o ser humano refém de um processo de escolarização por encomendas que não contribui para diminuir a desigualdade socioeconômica.

\section{Referências}

BRASIL. Ministério da Educação. Anais e Deliberações da I Conferência Nacional de Educação Profissional e Tecnológica. Brasília: Ministério da Educação, Secretaria de Educação Profissional e Tecnológica, 2007.

Ministério da Educação. Parecer CNE/CES n. ${ }^{\circ}$ 436/2001. Trata de Cursos Superiores de Tecnologia - Formação de Tecnólogos, p. 310-333. Relator Conselheiro Carlos Alberto Serpa de Oliveira. In: Educação Profissional e Tecnológica. Legislação Básica - Rede Federal, $7^{\text {a }}$ edição. Brasília, 2008.

Ministério da Educação. Parecer CNE/CES n. ${ }^{\circ}$ 29/2002. Trata das Diretrizes Curriculares Nacionais no Nível de Tecnólogo, p. 334-391. Relator Conselheiro Carlos Francisco Aparecido Cordão. In: Educação Profissional e Tecnológica. Legislação Básica - Rede Federal, $7^{\mathrm{a}}$ edição. Brasília, 2008. 
Ministério da Educação. Instituto Nacional de Estudos e Pesquisas Educacionais Anísio Teixeira (INEP). Diretoria de Estatísticas e Avaliação da Educação Superior (Deaes). Censo da Educação Superior 2004. Resumo Técnico. Brasília: DF. 2005. Disponível em: <http://www.INEP.gov.br/download/superior/2004/censosuperior/Resumo tecnicoCenso_2004.pdf> . Acesso em: 15 mar. 2008.

. Ministério da Educação. Instituto Nacional de Estudos e Pesquisas Educacionais Anísio Teixeira (INEP). Diretoria de Estatísticas e Avaliação da Educação Superior (Deaes). Censo da Educação Superior 2007. Resumo Técnico. Brasília: DF. 2009 Disponível em: <http://www.INEP.gov.br/download/superior/censo/2007/Resumo_tecnico_2007.pdf> Acesso em: 22 fev. 2009.

. Ministério da Educação. Instituto Nacional de Estudos e Pesquisas Educacionais Anísio Teixeira (INEP). Diretoria de Estatísticas e Avaliação da Educação Superior (Deaes). Resultados e Tendências da Educação Superior. Brasília: DF. Agosto de 2000. Disponível em:

<http://www.INEP.gov.br/imprensa/noticias/censo/superior/news00_3.htm>. Acesso em: 15 mar. 2008.

Ministério da Educação. Secretaria de Educação Profissional e Tecnológica. Princípios norteadores das engenharias nos institutos federais. Disponível em: <http://portalmec.gov.br/setec/>. Acesso em: $10 \mathrm{dez} .2008$.

Ministério da Educação. Secretaria de Educação Profissional e Tecnológica. Educação Profissional e Tecnológica. Concepção e Diretrizes para o Instituto Federal de Educação, Ciência e Tecnologia. Brasília: Ministério da Educação, Secretaria de Educação Profissional e Tecnológica, Junho de 2008. 43p.

Senado Federal. Lei $n^{\circ}$ 9.394, de 20 de dezembro de 1996. Estabelece as diretrizes e bases da educação nacional. Disponível em: $<$ http://www6.senado.gov.br/legislacao/ListaPublicacoes.action?id=102480> . Acesso em: 16 mar. 2008.

CONFEDERAÇÃO NACIONAL DA INDÚSTRIA. Mercado de Trabalho para o Engenheiro e Tecnólogo no Brasil, 2008. Disponível em: $<$ http://www.cni.org.br/portal/data/files/8A9015D0189E683801189E74A1DB132A/Pesqui sa\%20Inova\%20Engenharia\%202008.pdf, Acesso em: 22 fev. 2010.

DAGNINO, Renato. 2002. Enfoques sobre a relação Ciência, Tecnologia e Sociedade: Neutralidade e Determinismo. Disponível em: http://www.oei.es/salactsi/rdagnino3.htm>. Acesso em: 14 mai. 2008.

FRIGOTTO, Gaudêncio. Trabalho-educação e tecnologia: Treinamento polivalente ou formação politécnica? Educação e Realidade, Porto Alegre, 14 (1): 17-28, jan/jun. 1989.

LUKÁCS, György. Ontologia do ser social. São Paulo: Ciências Humanas, 1979. 174p. 
MANACORDA, Mario A. Marx e a pedagogia moderna. São Paulo: Cortez: Autores Associados, 1991.

MÉSZÁROS, István. O século XXI: socialismo ou barbárie? Tradução de Paulo Cesar Castanheira. São Paulo: Boitempo, 2003. 109p.

PÉREZ, Samuel Ubaldo. 2004. La educación politécnica vs educación polivalente: uma discusión pedagógica. Disponível em: http://www.fchst.unlpam.edu.ar/iciels/077.pdf >. Acesso em: 15 mai. 2008.

PRADO, Fernando Leme do. 2004. O tecnólogo. Disponível em: http://www.universia.com.br/carreira/materia.jsp?materia=4268>. Acesso em: $23 \mathrm{fev}$. 2008.

SAVIANI, Dermeval. 2003. O choque teórico da politecnia, p. 131-152. Trabalho, Educação, Saúde, v. 1, n. 1, mar. 2003. Disponível em: $<$ http://www.diaadia.pr.gov.br/det/arquivos/File/SEMANAPEDAGOGICA/21_O-choqueteorico-da-politecnia-Saviani.pdf>. Acesso em: 14 mai. 2008.

Trabalho e educação: fundamentos ontológicos e históricos. Revista Brasileira de Educação, v. 12, n. 34, jan./abr. 2007. Disponível em: < http://www.scielo.br/pdf/rbedu/v12n34/a12v1234.pdf $>$. Acesso em: 14 mai. 2008.

Notas:

${ }^{1}$ Graduado em Filosofia (1981). Possui mestrado em Educação pela Universidade Federal do Rio Grande do Sul (1986), doutorado em Educação pela Universidade Metodista de Piracicaba (1997) e pós-doutorado em Educação pela Universidade Federal do Rio Grande do Sul (2002). Trabalhou anteriormente na Universidade de Santa Cruz do Sul - UNISC (então FISC). Foi professor do Programa de Pós-Graduação em Educação da Universidade Federal de Santa Catarina até abril de 2010.

2 Graduado em Engenharia Elétrica pela Universidade Federal de Santa Catarina (1987), graduado em Licenciatura Plena Para Graduação de Professores pela Universidade do Estado de Santa Catarina (1987) e mestre em Engenharia de Produção pela Universidade Federal de Santa Catarina (2001). Atualmente é doutorando do Programa de Pós-Graduação em Educação (PPGE) da Universidade Federal de Santa Catarina. Integra o Grupo de Pesquisa Educação, Trabalho e Tecnologia vinculado ao IFSC, como seu coordenador.

${ }^{3}$ No tocante à politecnia, assumimos a conceituação de Frigotto, amplamente desenvolvida em "Trabalhoeducação e tecnologia: treinamento polivalente ou formação politécnica? Educação e Realidade, Porto Alegre, 14 (1): 17-28, jan./jun. 1989. Da data em que o trabalho de Frigotto foi publicado até hoje, a questão básica posta nesse trabalho não foi respondida no sentido afirmativo da instauração de uma educação tecnológica que insira densamente os conceitos de politecnia e de omnilateralidade de forma articulada. Diz Frigotto (1989, p.17): "no interior de relações sociais de produção que organizam o mundo do trabalho produtivo e improdutivo sob a lógica da 'unilateralidade' do homem, e que demandam a 'polivalência' do trabalhador, como instaurar, concretamente, uma prática educativa que se coloque na dimensão da 'omnilateralidade' do homem trabalhador, a qual requer uma formação politécnica?"

${ }^{4}$ Relativo ao conceito de omnilateralidade, ver a obra Marx e a pedagogia moderna, de Mario Alighiero Manacorda (São Paulo: Cortez: Autores Associados, 1991), especialmente o item III.4 O conceito de homem omnilateral (p. 78-86). Segundo essa obra (p.78), "Frente à realidade da alienação humana, na qual todo homem, alienado por outro, está alienado da própria natureza e o desenvolvimento positivo está alienado a uma esfera restrita, está a exigência da omnilateralidade, de um desenvolvimento total, completo, multilateral, em todos os sentidos das faculdades e das forças produtivas, das necessidades e da capacidade da sua satisfação".

${ }^{5} \mathrm{Na}$ tentativa de entender o que se chama técnica e tecnologia e a sua influência na existência humana, se não submetermos nossas considerações aos critérios da história da realidade biológica e social do homem, 
permaneceremos desorientados, procurando tão somente compreender uma suposta realidade em si, denominada "técnica', bem como os produtos, os mecanismos, os procedimentos nos quais se materializa, e o tempo histórico (linear) em que aparecem, chegando à marca "era tecnológica", sem notar que estamos procedendo às cegas, porque não nos munimos do essencial, isto é, das categorias lógico-dialéticas para pensar a tecnologia, as suas implicações e desdobramentos histórico-sociais. (VIEIRA PINTO, 2005, p.70).

${ }^{6} \mathrm{Na}$ situação de hoje, o capital não tem mais condições de se preocupar com o "aumento do círculo de consumo", para benefício do "indivíduo social pleno" de quem falava Marx, mas apenas com sua reprodução ampliada a qualquer custo, que pode ser assegurada, pelo menos por algum tempo, por várias modalidades de destruição, eis que do perverso ponto de vista do "processo de realização" do capital, consumo e destruição são equivalentes funcionais (MÉSZÁROS, 2003, p.21-22).

7 O Conselho Nacional de Educação é um órgão colegiado integrante da estrutura de administração direta do MEC e foi criado nos termos da Lei 9.131, de 24 de novembro de 1995. As atribuições do Conselho são normativas, deliberativas e de assessoramento ao Ministro de Estado da Educação, no desempenho das funções e atribuições do poder público federal em matéria de educação, cabendo-lhe formular e avaliar a política nacional de educação, zelar pela qualidade do ensino, zelar pelo cumprimento da legislação educacional e assegurar a participação da sociedade no aprimoramento da educação brasileira (PORTAL MEC, 2008).

${ }^{8}$ Os cursos tecnológicos começaram no Brasil a partir de 1808, com a vinda da família real, ano em que Dom João VI criou a Academia da Marinha e, dois anos depois, a Academia Real Militar, além de instalar hospitais militares para funcionarem como escolas técnicas. Portanto, a educação formal brasileira começa com a Educação Tecnológica (PRADO, 2004, p.1). Trata-se, obviamente, de um tempo-espaço com outras necessidades para a produção da existência humana e da reprodução ampliada da classe dominante. Hoje os Cursos Tecnológicos são parte de um complexo educativo que avança e recua conforme as necessidades da reprodução (ampliada) do capital em sua atual configuração (entre outros, com problemas relativos à reprodução ampliada e à seletividade mercadocêntrica dos espaços e grupos humanos face o fim histórico das fronteiras expasionistas). No que tange aos aspectos da educação profissional dos tecnólogos hoje, é importante destacar que o modelo praticado não se refere a uma educação nos moldes da tradição (formação em nível médio). Trata-se de uma modalidade de educação denominada de Educação Tecnológica, referenciada a uma formação de terceiro grau; portanto, ensino superior.

${ }^{9}$ Afora a expansão privatista (em termos relativos de vagas) no âmbito do binômio Educação SuperiorEducação Tecnológica, não há como deixar de considerar que o imbricamento dos conceitos de educaçãomercado-currículo muitas vezes também implica a "promiscuidade" público-privado.

${ }^{10}$ No capitalismo, a ciência afirmou-se enquanto uma superestrutura especial. A ligação da ciência com os Estados capitalistas, a partir da elaboração de novas ideias, conhecimentos e valores importantes para sua consolidação interna, e na disputa entre e com capital, através de seu potencial de gerar mais valia relativa, levaram-na a ser um dos princípios motores da expansão do sistema capitalista. A partir de meados do século XIX, as novas formas de exploração do trabalhador, a complexificação da extração do excedente no processo de trabalho e da subordinação ganham características que marcam profundamente o modo de funcionamento do capitalismo contemporâneo. (DAGNINO, 2002, p.12).

Recebido em: $\quad 01 / 10 / 10$

Aprovado em: 10/02/11 